\title{
Factors related to the improvement in quality of life for depressed inpatients treated with fluoxetine
}

\author{
Wei-Cheng Yang ${ }^{1}$, Ching-Hua Lin ${ }^{1,2^{*}}$, Fu-Chiang Wang ${ }^{1}$ and Mei-Jou Lu
}

\begin{abstract}
Background: The aim of this study was to explore the relationships between depressive symptoms and healthrelated quality of life (HRQOL) measurements for inpatients with major depressive disorder (MDD) before and after 6-week fluoxetine treatment, and to elucidate the factors related to the HRQOL changes.

Methods: A total of 131 inpatients with MDD were enrolled to receive $20 \mathrm{mg}$ of fluoxetine for 6 weeks. Symptom severity and adverse events were assessed at weeks 0, 1, 2, 3, 4, and 6 using the 17-item Hamilton Depression Rating Scale (HAMD-17) and UKU Side Effect Rating Scale, respectively. HRQOL was measured using the Short Form 36 (SF-36), including 8 subscales, physical component summary (PCS) and mental component summary (MCS), at baseline and week 6 . Spearman's coefficient, Cohen's d, and multiple linear regression model were used for statistical analysis.
\end{abstract}

Results: One hundred and six patients completing all measures at weeks 0 and 6 entered the analysis. HAMD-17 negatively correlated with SF-36 at baseline and week 6. The HAMD-17 had a larger effect size than SF-36. MCS, rather than PCS, showed statistically significant improvement. After using multiple linear regression analysis, age at onset, HAMD-17 score change, and number of adverse events reported during the trial period were related to MCS change after adjusting for confounding variables.

Conclusions: Fluoxetine treatment was associated with an improvement in depressive symptomology and HRQOL. Depressive symptoms had a greater extent of change than HRQOL. Clinicians must consider the negative effects of adverse events caused by antidepressants on the improvement of HRQOL.

Trial registration: http://clinicaltrials.gov, NCT01075529, retrospectively registered 24/2/2010.

\section{Background}

Health-related quality of life (HRQOL) has been defined as "those aspects of self-perceived well-being that are related to or affected by the presence of disease or treatment [1]." The assessment of HRQOL should consider patients' subjective views of their life circumstances [2], including perceptions of social relationships, physical health, mental heath, functioning in daily activities and work, and an overall sense of well-being [3]. Compared to the general population and patients with other chronic diseases, such

\footnotetext{
*Correspondence: chua.lin@msa.hinet.net

${ }^{1}$ Kaohsiung Municipal Kai-Syuan Psychiatric Hospital, No.130, Kaisyuan 2nd Road, Lingya District, Kaohsiung City 80276, Taiwan

2Department of Psychiatry, Faculty of Medicine, College of Medicine, Kaohsiung Medical University, No.100, Shihcyuan 1st Road, Sanmin District, Kaohsiung City 80708, Taiwan
}

as diabetes, arthritis or cardiovascular disease, HRQOL is substantially reduced in patients suffering from major depressive disorder (MDD) [4, 5]. Depressed patients typically regard their well-being, social functioning and living conditions as being worse than they appear to independent observers [6].

There is an increasing demand to adopt HRQOL as an outcome measure for clinical trials and health care policy [7]. HRQOL measurement should consider patients' subjective views of their life circumstances [8]. This may provide a more extensive assessment of treatment outcomes than those based solely on improvement in symptoms of depression. For example, while antidepressant medication may decrease depressive symptoms, it may also induce unpleasant adverse events that impair the 
patient's HRQOL [9]. Souetre et al. [10] conducted a trial to compare the effect of fluoxetine vs. tricyclic antidepressants (TCAs) on HRQOL of patients with MDD. Although depressive symptoms were comparable for the 2 groups, the fluoxetine group had HRQOL superior to that of the TCAs group after adjusting for confounding variables. The authors concluded that one of the reasons for a superior level of HRQOL may have been due to differences in drug-related adverse events. Therefore, a patient's perception of health and well-being is not associated with symptom reduction alone. HRQOL could be regarded as a kind of risk-benefit analysis. The American Psychiatric Association guideline for the treatment of patients with MDD [11] suggests that decreases in depressive symptoms and improvement in HRQOL are recognized as the goals in treating depressed patients. In essence, effective treatment should lead to symptom reduction and improvement in HRQOL.

To date, there is still no study to investigate the level of HRQOL change after treatment for depressed patients negatively impacted by adverse events occurred during the trial period. The aim of this study was to explore the relationships between depressive symptoms and HRQOL measurements for MDD inpatients before and after a 6week fluoxetine treatment, and to elucidate the factors related to the HRQOL changes.

\section{Methods}

\section{Subjects}

The current study was part of a clinical trial, documented elsewhere [12]. The trial was approved by Kai-Syuan Psychiatric Hospital's institutional review board and conducted in accordance with both Good Clinical Practice procedures and the most recent revision of the Declaration of Helsinki. Written, informed consent was obtained from all participants after a full explanation of study aims and procedures. This study was registered on http://clinicaltrials.gov (Identifier number: NCT01075529).

As previously described in detail [12], all MDD patients newly hospitalized for acute treatment were screened and evaluated by three board-certified psychiatrists using the Structured Clinical Interview for DSMIV [13] to ensure diagnostic accuracy. Han Chinese patients in Taiwan were enrolled in this study if they: 1) were physically healthy with normal laboratory tests (including electrocardiography and chest X-ray), 2) were aged 18-70 years, and 3) satisfied DSM-IV criteria for MDD. The exclusion criteria were: 1) a baseline score of 17-item Hamilton Depression Rating Scale (HAMD-17) $[14]<18,2)$ a Clinical Global Impression of Severity (CGI-S) [15] < 4, 3) psychotic depression, bipolar I or II disorder, schizophrenia, or any other psychotic disorder, 4) a DSM-IV diagnosis of substance abuse or dependence (including alcohol) within the past 6 months, 5) mental disorders due to organic factors, 6) severe cognitive impairment, 7) initiating or ending formal psychotherapy within six weeks prior to enrollment, 8) receiving formal psychotherapy during the trial period, 9) Treatment-resistant depression was defined as a lack of response to 2 or more adequate trials of different classes of antidepressants [16]. An adequate trial is defined as 4-6 weeks of treatment with an antidepressant at a dosage considered therapeutic [17], 10) a history of poor response to fluoxetine (defined as no obvious clinical improvement after receiving at least $20 \mathrm{mg} /$ day of fluoxetine for 4 weeks as reported by medical record, the patients, or their family) or intolerance to fluoxetine, 11) a history of electroconvulsive therapy, and 11) pregnancy or lactation.

\section{Procedures and assessments}

After a washout period of at least $72 \mathrm{~h}$, patients received open-label fluoxetine treatment at a fixed dose of $20 \mathrm{mg}$ daily for 6 weeks. During the course of treatment, psychiatrists had the option of adding certain anxiolytic and/or sedative-hypnotic medications for brief periods, based on clinical necessity. No other psychotropic agents were used at bedtime to treat insomnia. Drug adherence was monitored and ensured by psychiatric nurses. Demographic and clinical characteristics of the participants were gathered at baseline. Age at onset was regarded as the age at which the first major depressive episode occurred.

Depression severity was assessed at baseline, and again at weeks $1,2,3,4$, and 6 by three board-certified psychiatrists using the HAMD-17. Inter-rater reliability of HAMD-17 was analyzed with the ANOVA test. The intraclass correlation coefficient of reliability during prestudy training was 0.95 among the raters for assessing 10 patients. To maintain high interrater reliability and prevent rater drift, raters met at least once a month for training and reliability retesting.

Adverse-event burden was assessed by the Utvalg for Kliniske Undersogelser Side Effect Rating Scale (UKU) [18] and by the registration of adverse events at baseline and at weeks $1,2,3,4$, and 6 . UKU is a clinician-rated scale with 48 items which include psychic subscale, neurological subscale, autonomic subscale, and other subscale. UKU contains a Likert scale of $0-3$ for degree of severity, and is commonly used to assess the tolerability of antidepressants in clinical trials [19, 20]. A score of 1,2 or 3 on any UKU item that first occurred or worsened during treatment indicates an adverse event. Therefore, adverse events included those absent at baseline and the worsening of an adverse event, already present at baseline, during the trial [21]. The number of adverse events reported during the trial period is used to determine the adverse-event burden. 
HRQOL measurement included Medical Outcomes Study Short-Form-36 (SF-36) [22] at baseline and week 6. The SF-36 is comprised of the physical component summary (PCS) which measures physical health, and the mental component summary (MCS) which measures mental health. PCS includes 4 subscales: 1) physical functioning, 2) role physical limitations, 3) body pain, 4) general health; MCS includes 4 subscales: 1) vitality, 2) social functioning, 3) role emotional limitations, and 4) mental health. SF-36 raw scores were processed according to the user manual to obtain standardized scores for all 8 SF-36 subscales, PCS and MCS [23]. Scores for the 8 SF-36 subscales range from 0 to 100 , with a higher score representing better HRQOL. The PCS and MCS were standardized according to general population means and variances to produce scores with a common mean of 50 and standard deviation of 10 (T-scores). Thus, any score $<50$ represents a reduction from "normal" health. At the moment no Taiwanese population data on the SF-36 exists, therefore the population mean and standard deviation are from the 1998 general U.S. population [24]. The Taiwanese version of the SF-36 shows good validity and reliability [25] and in the current sample the reliabilities were estimated at 0.78 (week 0) and 0.90 (week 6). Since the SF-36 is a selfreported questionnaire. For illiterate patients, SF-36 was completed during face-to-face interviews.

\section{Statistical analysis}

The data were analyzed using IBM SPSS Statistics for Windows, version 20. Statistical significance was set at $p<0.05$. Descriptive statistics were listed for the demographic and clinical variables of subjects.

Spearman's coefficient was used to examine the correlations between HAMD-17 and SF-36 (i.e., scores of the 8 subscales, PCS, and MCS) at week 0 and again at week 6. Pre-test and post-test HAMD-17 and SF-36 scores were compared using paired t-test. Cohen's d [26] was computed as a measure of the pre-post effect sizes for HAMD-17 and SF-36. Effect size was defined as the mean of difference between baseline and post-treatment scores for each measure divided by the standard deviation of difference [27]. A d-value of 0.20 indicates a small effect size, 0.50 medium effect size, and 0.80 large effect size [26]. Effect size provides an estimate of the magnitude of between-group differences on a standard scale. Large effect sizes demonstrate clinically relevant improvement at the end point. Effect size is a unitless measure, thus appropriate for comparisons involving scales with different metrics [28]. Therefore, the degrees of improvement could be compared among the different subscales.

A multiple linear regression model was used to explore the variables associated with HRQOL changes as measured by PCS or MCS. The multiple linear regression model was bootstrapped (bootstrap samples $=1000$ ) to obtain statistically more robust results for the relatively small sample size. These variables included sex, age, age at onset, number of previous depressive episodes, baseline PCS or MCS, HAMD-17 score changes, and number of adverse events reported during the trial period. Variance Inflation Factor (VIF) values larger than 10 were regarded as having presence of multicollinearity [29].

\section{Results}

A total of 131 acutely ill MDD inpatients was enrolled. One hundred and six (80.9\%) of 131 patients who completed all measures at baseline and week 6 were included in the analysis. The participant selection process is shown in Fig. 1. There were no statistical significances between the patients included $(n=106)$ and those without $(n=25)$ with respect to sex $(p=0.276)$, age $(p=0.219)$, age at onset $(p=0.110)$, number of previous episodes $(p=0.491)$, and baseline HAMD-17 $(p=0.733)$ (data not shown in the Table). Table 1 lists the demographic and clinical characteristics of the subjects

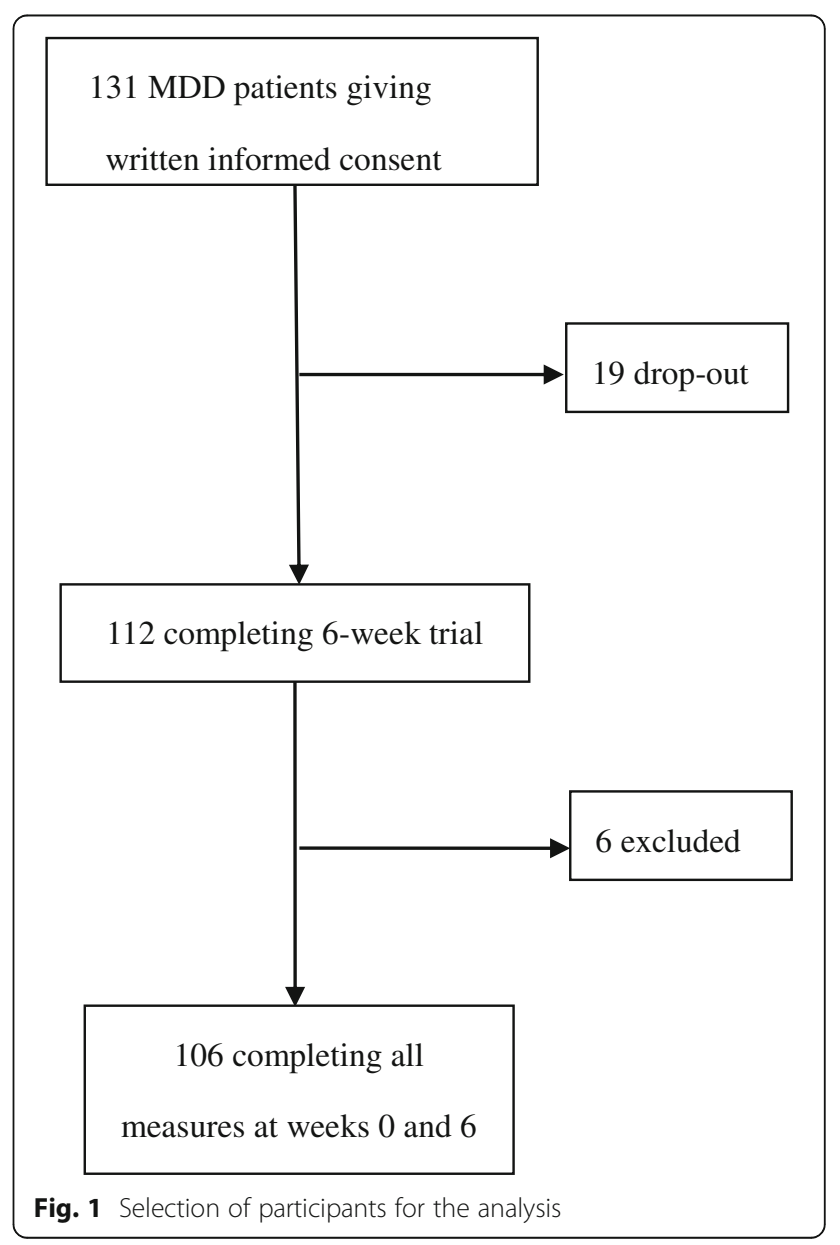


Table 1 Demographic and clinical variables of subjects $(n=106)$ at baseline

\begin{tabular}{|c|c|}
\hline Variables & Distribution \\
\hline Sex-male, \% & $23(21.7)$ \\
\hline Age, mean (SD), y & $45.8(11.2)$ \\
\hline Age at onset, mean (SD), y & $39.6(12.0)$ \\
\hline Number of previous episodes, mean (SD) & $2.5(1.9)$ \\
\hline Number of adverse events, mean (SD) & $4.6(3.6)$ \\
\hline HAMD-17 ${ }^{a}$ score, mean (SD) & $31.4(6.4)$ \\
\hline
\end{tabular}

included. The mean HAMD-17 \pm SD of score of $31.4 \pm$ 6.4 at baseline reflected fairly severely depressed subjects. The mean of number of adverse events reported during the trial period was $4.6 \pm 3.6$. The top three categorical adverse events were dizziness $(n=42,39.6 \%)$, reduced salivation $(n=40,37.7 \%)$, and polyuria/polydipsia $(n=33,31.1 \%)$.

HAMD-17 scores negatively correlated with 8 subscales, PCS, and MCS of SF-36, regardless of whether at baseline or at week 6 (Table 2). Additionally, these correlations improved markedly at week 6 .

HAMD-17 and SF-36 at baseline and week 6 are listed in Table 3. HAMD-17 decreased significantly from 31.4 \pm 6.4 to $13.7 \pm 8.3$. Compared to Taiwanese norms [25], baseline measures of HRQOL were significantly impaired. Among 8 SF-36 subscales, improvements ranged from an increase of $2.4 \pm 23.7$ points in the physical functioning subscale, and an increase of $17.6 \pm 40.0$ points in the role emotional limitations subscale. However, 8 SF-36 subscales after the 6-week treatment were still lower than those of Taiwanese norms. All SF-36 subscales, but not physical functioning, improved significantly after treatment. The greatest improvements were found in the subscales measuring mental health (i.e., mental health, role emotional limitations, and vitality) as opposed to physical health (i.e., physical functioning, role physical limitations, and body pain). The observed improvement of PCS was only minimal, but this improvement was not statistically significant. The MCS showed statistically significant improvement after the 6week treatment (Table 3). The pre-post effect sizes for PCS and MCS were 0.142 and 0.548, respectively, indicating that fluoxetine treatment was more strongly associated with improvements in mental health than physical health.

Consequently, a multiple linear regression model using the bootstrap method was applied to analyze only the predictors related to MCS change during treatment. Age at onset of major depressive episode, HAMD-17 score change, and the number of adverse events were significant predictors associated with MCS change after adjusting for sex, age, number of previous episodes, and baseline MCS. All VIFs were less than 10, and indicated no presence of multicollinearity in the model (Table 4). The non-standardized regression weights (B) in Table 4 require interpretation. For example, after adjusting for other predictors, patients increased likelihood of later age at onset of illness of having an increased MCS score (per year increased in age at onset they gained 0.283 points in MCS).

\section{Discussion}

The first main finding of the current study was that symptomatic changes only accounted for a limited amount of variance in HRQOL changes. The second was that being younger at onset and adverse events during treatment hindered improvement in HRQOL. Our results replicated previous findings, that treating MDD inpatients with antidepressants is efficacious in relieving depression symptoms and improving HRQOL [30, 31].

Table 2 Correlations between HAMD-17 and SF-36 for both instruments measured at week 0 and measured at week 6 ( $n=106)$

\begin{tabular}{lllr}
\hline & HAMD-17 at week 0 & HAMD-17 at week 6 \\
\hline SF-36 at week 0 & & SF-36 at week 6 & $r^{2}$ \\
Physical functioning & $r=-0.313^{* *}$ & Physical functioning & $r^{* *}$ \\
Role physical limitations & $r=-0.251^{* *}$ & Role physical limitations & $r=-0.433^{* *}$ \\
Bodily pain & $r=-0.208^{*}$ & Bodily pain & $r=-0.484^{* *}$ \\
General health & $r=-0.390^{* *}$ & General health & $r=-0.713^{* *}$ \\
Vitality & $r=-0.413^{* *}$ & Vitality & $r=-0.699^{* *}$ \\
Social functioning & $r=-0.211^{*}$ & Social functioning & $r=-0.609^{* *}$ \\
Role emotional limitations & $r=-0.198^{*}$ & Role emotional limitations & $r=-0.493^{* *}$ \\
Mental health & $r=-0.377^{* *}$ & Mental health & $r=-0.662^{* *}$ \\
Physical component summary & $r=-0.311^{* *}$ & Physical component summary & $r=-0.569^{* *}$ \\
Mental component summary & $r=-0.289^{* *}$ & Mental component summary & $r=-0.657^{* *}$ \\
\hline
\end{tabular}

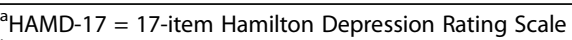

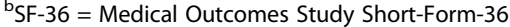

${ }^{*} p<0.05,{ }^{* *} p<0.01$ 
Table 3 Pre-post comparisons of HAMD-17 ${ }^{\mathrm{a}}$ and SF-36 ${ }^{\mathrm{b}}$ for patients completing the 6 -week treatment $(n=106)$

\begin{tabular}{|c|c|c|c|c|c|c|}
\hline Measure & $\begin{array}{l}\text { Taiwanese norms } \\
\text { (Mean } \pm \text { SD) }\end{array}$ & $\begin{array}{l}\text { Week } 0 \\
(\text { Mean } \pm \text { SD) }\end{array}$ & $\begin{array}{l}\text { Week } 6 \\
(\text { Mean } \pm \text { SD) }\end{array}$ & $\begin{array}{l}\text { Difference } \\
\text { (Mean } \pm \text { SD) }\end{array}$ & $p$ & Effect size \\
\hline HAMD-17 & & $31.4 \pm 6.4$ & $13.7 \pm 8.3$ & $-17.7 \pm 8.5$ & $<0.001^{*}$ & -2.093 \\
\hline \multicolumn{7}{|l|}{ SF-36 } \\
\hline Physical functioning & $92.24 \pm 16.16$ & $61.5 \pm 25.7$ & $63.9 \pm 25.4$ & $2.4 \pm 23.7$ & 0.299 & 0.101 \\
\hline Role physical limitations & $83.65 \pm 33.27$ & $15.1 \pm 30.8$ & $28.5 \pm 41.9$ & $13.4 \pm 45.1$ & $0.003^{*}$ & 0.298 \\
\hline Bodily pain & $84.84 \pm 19.42$ & $45.3 \pm 26.1$ & $50.9 \pm 29.2$ & $5.6 \pm 24.1$ & $0.018^{*}$ & 0.233 \\
\hline General Health & $69.29 \pm 21.27$ & $28.0 \pm 22.5$ & $35.9 \pm 26.4$ & $7.9 \pm 22.8$ & $<0.001^{*}$ & 0.348 \\
\hline Vitality & $68.27 \pm 18.66$ & $24.6 \pm 19.6$ & $33.7 \pm 23.2$ & $9.2 \pm 21.9$ & $<0.001^{*}$ & 0.417 \\
\hline Social functioning & $86.81 \pm 17.05$ & $33.8 \pm 22.9$ & $43.0 \pm 26.2$ & $9.2 \pm 27.2$ & $<0.001^{*}$ & 0.338 \\
\hline Role emotional limitations & $79.40 \pm 36.07$ & $5.7 \pm 17.5$ & $23.3 \pm 39.1$ & $17.6 \pm 40.0$ & $<0.001^{*}$ & 0.441 \\
\hline Mental health & $73.01 \pm 16.55$ & $26.7 \pm 19.3$ & $37.6 \pm 22.2$ & $10.9 \pm 23.9$ & $<0.001^{*}$ & 0.457 \\
\hline Physical component summary & & $39.3 \pm 10.0$ & $40.6 \pm 10.6$ & $1.3 \pm 9.3$ & 0.148 & 0.142 \\
\hline Mental component summary & & $23.3 \pm 8.62$ & $29.7 \pm 11.3$ & $6.4 \pm 11.6$ & $<0.001^{*}$ & 0.548 \\
\hline
\end{tabular}

${ }^{\mathrm{a}}$ HAMD-17 = 17-item Hamilton Depression Rating Scale

${ }^{\mathrm{b}} \mathrm{SF}-36$ = Medical Outcomes Study Short-Form-36

*Statistically significant

Similar to results seen in other studies $[5,9,32]$, there was an inversely significant correlation between depression severity and HRQOL measurements at baseline and again at week 6 (Table 2). Table 2 also shows that the correlations between baseline HAMD-17 and SF-36 (i.e., 8 subscales, PCS and MC) increased after 6 weeks of treatment. One possibility is that since patients responded differently to treatment, the variation in scores got larger during treatment, and therefore, even if the population covariances between measures did not change at all, the correlations consequently may increase. Another is that severity of illness also affected the level of correlation. Patients with severe illness may have difficulty completing the self-reported questionnaire (e.g., SF-36) on their own, while their selfperception and cognitive distortion may not reflect reality for rating scales [33-35]. Therefore, depressed patients with severe symptomatology (e.g., at baseline) may underestimate their HRQOL [34]. Clinicians tend to recognize severe illness based on non-verbal evidence
[36]. As patients' conditions improve after treatment, their verbal reports become more important for less severe illness, because they are more capable of clearly identifying their problems [35].

Improvements varied in magnitude measured by effect sizes across SF-36 subscales, with the greatest improvements observed in the subscales that focus more on mental health as opposed to physical health (Table 3). Table 3 also shows that physical functioning score was rather high, but the role physical limitations score, body pain score, and general health score were low. There are several explanations. First, all participants were physically healthy with normal laboratory tests. A growing body of evidence suggests that pain and depression may operate within similar areas of the brain that regulate both mood and the affective components of pain [37]. Depression and pain may interact bidirectionally [3840], therefore it is reasonable that physical functioning was rather high in comparison to the other scores, and body pain was negatively affected by depression severity.

Table 4 Multiple linear regression model with the changes of mental component summary (MCS) as a dependent variable $(n=106)$

\begin{tabular}{lllllr}
\hline Dependent variable & Independent variable & $B^{\mathrm{a}}$ & $\mathrm{SE}^{\mathrm{b}}$ & $\mathrm{p}$ & Adjusted R $^{2} \mathrm{VIF}^{\mathrm{C}}$ \\
\hline MCS change & Sex & 0.681 & 2.195 & 0.756 & 0.434 \\
& Age & -0.019 & 0.105 & 0.850 & 2.565 \\
& Age at onset & 0.283 & 0.107 & $0.006^{*}$ & 2.949 \\
Number of previous episodes & 0.151 & 0.549 & 0.783 & 1.424 \\
& HAMD-17 score change & -0.443 & 0.118 & $0.001^{*}$ & 1.160 \\
& Number of adverse events & -0.615 & 0.238 & $0.008^{*}$ & 1.197 \\
Baseline MCS & -0.570 & 0.115 & $0.001^{*}$ & 1.032 \\
\hline
\end{tabular}


Second, a moderate correlation existed between role physical limitations and role emotional limitations before $(r=0.458, \boldsymbol{p}<\mathbf{0 . 0 0 1})$ and after trial $(r=0.676$, $\boldsymbol{p}<\mathbf{0 . 0 0 1}$ ). Some severely depressed patients may have troubles realizing whether their reduction of working/activities duration came from physical difficulties (i.e., items for role physical limitations) or from emotional difficulties (i.e., items for role emotional limitations). Third, using the items of SF-36 (i.e., 11a. 11b, 11c, and 11d) to measure general heath only focuses on patients' health conditions rather than highlighting mental health. The mean (SD) scores of item 17 of HAMD-17 (i.e., insight) before and after the trial were $0.5(0.6)$ and 0.2 (0.4), respectively (data not shown in the Table). This suggests that most of the patients acknowledged being ill and unhealthy, thereby leading the low score in general health. However, another Taiwanese study $(n=95)$ [41] used the 8 subscales of SF-36 to measure HRQOL for MDD outpatients receiving $75 \mathrm{mg}$ daily of venlafaxine before and after 1-month treatment. Their results were comparable to our findings, that the score of physical functioning $(72.5 \pm 20.9$ to $82.7 \pm 17.8)$ was rather high, but the scores for the role physical limitations $(24.7 \pm 34.1$ to $55.3 \pm 39.3)$, body pain $(47.6 \pm 19.2$ to $62.2 \pm 21.6)$, and general health $(31.3 \pm 17.4$ to $47.4 \pm$ 20.7) were low. Compared to a study [42] conducted in the U.S. for depressed patients treated with $20 \mathrm{mg}$ daily of fluoxetine for 3 months, the mean score of physical functioning (73.2 to 75.8) was highest, but the mean score of vitality was very low (28.8 to 50.5$)$. These results are similar to ours. However, the mean scores of role physical limitations (63.5 to 73.6) and general health score (57.7 to 63.3) were not too low, which indicates that cultural and ethnic factors should be explored in further studies. Symptom improvements rated by HAMD-17 had larger effect sizes (absolute value $=2.093$ ) than SF-36 (Table 3). This means that depressive symptoms had a greater extent of change than HRQOL after the 6-week treatment [7]. This finding was also in accordance with other studies [43-45]. Furthermore, this finding was highly in line with theoretical models of response in mental health, especially the "phase model" proposed by Howard et al. [46], which posits that first a general hope factor causes a response similar to a placebo effect, then specific symptoms change and anything connected to the interpersonal and real life setting of the patients responds quite a bit later. Health-related quality of life can be seen as one indicator of this last area/ phase of treatment response. However, SF-36 in the subjects after treatment was still lower than that of Taiwanese norms (Table 3). McCall et al. [47] concluded that maximal improvement in HRQOL may lag weeks or months behind maximum symptom improvement. Therefore, HRQOL enhancement therapies, e.g., combinations of pharmacotherapy with psychotherapy [48], were still necessary after the trial.

SF-36 summary scores showed that MCS rather than PCS improved significantly after treatment. Our results were also consistent with previous antidepressant studies showing that PCS scores do not, or only marginally, change with time for depressed patients treated with antidepressant agents $[45,49,50]$. As MDD is a mental health problem, it is rational to assume that the mental health subscales improve more (i.e., greater effect sizes) than do physical health subscales after treatment. Physical functioning is highly correlated with PCS, and mental health correlates highly with MCS. MCS is designed to provide a valid summary of information contained in the 8 SF-36 subscales for both mental health status and changes over time. MCS has been established as a sensitive outcome measure in studies of clinical depression [51].

In the multiple linear regression model, greater MCS improvement after the 6-week fluoxetine use could be predicted for subjects with older age onset of MDD (Table 4). This result is consistent with the study by Moses et al. [52]. Early-onset MDD has been reported to represent developmental pathways characterized by a distinct set of sociodemographic and clinical features $[53,54]$, and is associated with a higher level of comorbidity and impairment, as well as significant genetic loading [55]. The greater improvement of subjects with older age onset of MDD may be due to their having developed better psychosocial contexts for quick improvement in HRQOL [52].

Previous studies $[56,57]$ have concluded that improvement in HRQOL correlates highly with improvement in depressive symptoms. As expected, the current study shows that the amelioration of depressive symptoms measured by HAMD-17 was still accompanied by improvements in MCS after adjusting for other variables (Table 4).

Adverse events due to antidepressants are widely believed to have a negative impact on HRQOL $[49,58]$. Our results reveal that the number of adverse events reported during the trial period was negatively related to patients' MCS improvement. This finding was comparable to that of other studies, in which antidepressants' adverse events are associated with decreased HRQOL $[59,60]$. Adverse events subsequent to fluoxetine use have been reported to be relatively mild and usually begin early in the course of therapy [61]. The SF-36 is designed to assess the HRQOL over the previous 4 weeks [22], so it is reasonable that SF-36 measurements cover the early course of fluoxetine treatment. In the present study, the number of adverse events is only negatively correlated with changes of mental health subscales ( $r=-0.196, \boldsymbol{p}=\mathbf{0 . 0 4 4}$ for role emotional limitations to 
$r=-0.327, \boldsymbol{p}=\mathbf{0 . 0 0 1}$ for mental health) rather than physical health subscales (data not shown in the Table). Adverse events are supposed to generate psychological distress rather than physical injury to patients, and therefore influence mental health much more than physical health. Actually, no severe adverse events were reported during the trial period. If we excluded the number of adverse events from the multiple linear regression model, the adjusted $R^{2}$ changed from 0.434 (Table 4) to 0.406 (data not shown in the Table). However, adverse events could be decreased with appropriate intervention [62]. In short, the number of adverse events could be considered a modifiable risk factor. Although the influence of adverse events on HRQOL is relatively mild; it should not be neglected. Fluoxetine might be a two-edged sword in terms of HRQOL improvement for patients with MDD. Adverse events may compromise patients' HRQOL improvement, which may further compromise treatment adherence. Psychiatrists must help patients identify and manage these adverse events.

In the present study, multiple linear regression model (Table 4) explained approximately $43.4 \%$ of the variance (adjusted $R^{2}=43.4 \%$ ) of MCS improvement, suggesting that improvement in depressive symptoms may not accurately represent improvement in HRQOL. The mechanism affecting improvement in HRQOL for patients with MDD is complex and multifactorial. Besides age at onset, symptom improvement, and number of adverse events, other potential variables related to HRQOL improvement require further exploration in future studies.

There were some limitations to the method of interpreting the results. First, use of a single site with a relatively small sample size limited the generalizability of our results. Second, assessments were performed during the acute stage, and the stability of these findings was not evaluated through time. The study period of 6 weeks was relatively short when considering the total duration of depression. However, it was fairly long, and sufficient for inpatient trials to detect initial antidepressant responses. Third, there are other HRQOL scales available for subjects, and different scales may yield different results. Fourth, this was an open-label design without a control group. Because of this, it was difficult to establish the degree to which clinical improvements were due to fluoxetine treatment, placebo effect, other psychiatric interventions, or the natural course of MDD. For example, hospitalization itself can be a significant nonpharmacological therapeutic factor affecting clinical improvement in patients with MDD. Therefore, this study did not establish a causal link between fluoxetine and any changes observed, since no control group was presented. Although, without a placebo-controlled group, the impact of placebo effects on the current study could not be estimated, it is unlikely the clinical response was solely attributable to placebo effects for the following reasons: first, the response (i.e., a reduction of $50 \%$ or more of the HAMD-17) rate $(=56.9 \%)$ was too high to be accounted for by the typical placebo effects, i.e., around $30 \%$, as estimated from past clinical placebocontrolled antidepressant trials [63]; second, it has been demonstrated that patients with more severe depression are less susceptible to placebo effect [64]. However, a meta-analysis study [65] demonstrates that drug-placebo differences in antidepressant efficacy increase as a function of baseline severity, but are relatively small even for severely depressed patients. Finally, our sample was comprised of the most severely affected MDD patients who required hospitalization. Also, inpatients' clinical situation is not very representative of outpatients.

\section{Conclusions}

Our study showed that for hospitalized patients with MDD, fluoxetine improved not only depressive symptoms but also most aspects of HRQOL. Within the 6week trial period, depressive symptoms showed a greater degree of change than HRQOL measurement. Age at onset of major depressive episode, HAMD-17 score change, and the number of adverse events experienced during the trial period were associated with MCS improvements after adjusting for sex, age, number of previous episodes, and baseline MCS. The regression model accounted for approximately $43.3 \%$ of the variance in MCS improvement. Further study is required for determining the long-term improvement in HRQOL, and the efficacy of other treatment modalities in improving HRQOL.

\section{Abbreviations}

CGI-S: Clinical Global Impression of Severity; HAMD-17: 17-item Hamilton Depression Rating Scale; HRQOL: Health-related quality of life; MCS: Mental component summary; MDD: Major depressive disorder; PCS: Physical component summary; SF-36: Medical outcomes study short-form-36; TCAs: Tricyclic antidepressants; UKU: Utvalg for Kliniske Undersogelser

\section{Acknowledgements}

We would like to thank all the participants for this study. The authors thank Dr. Huey-Shyan Lin for the contribution of multiple linear regression model.

\section{Funding}

This study was funded by the Kai-Syuan Psychiatric Hospital (KSPH-2007-16) and the Ministry of Science and Technology, Taiwan (MOST-103-2314-B-280001-MY3).

\section{Availability of data and materials}

The data are available from the corresponding author on reasonable request after approval by Kai-Syuan Psychiatric Hospital's institutional review board, but not publicly available.

\section{Authors' contributions}

Dr.Yang (first author) analyzed the data and wrote draft of the manuscript. Dr. Lin (corresponding author) directed the study and revised the manuscript. Dr. Wang (third author) and Miss Lu (fourth author) managed the literature searches and analyses. All authors contributed to and have approved the final manuscript. 


\section{Ethics approval and consent to participate}

The trial was approved by Kai-Syuan Psychiatric Hospital's institutional review board. Written, informed consent was obtained from all participants.

\section{Consent to publication}

Not applicable.

\section{Competing interests}

The authors declare no competing interests.

\section{Publisher's Note}

Springer Nature remains neutral with regard to jurisdictional claims in published maps and institutional affiliations.

\section{Received: 9 March 2017 Accepted: 16 August 2017}

\section{Published online: 25 August 2017}

\section{References}

1. Ebrahim S. Clinical and public health perspectives and applications of healthrelated quality of life measurement. Soc Sci Med. 1995:41(10):1383-94

2. Mendlowicz MV, Stein MB. Quality of life in individuals with anxiety disorders. Am J Psychiatry. 2000;157(5):669-82.

3. Patrick DL, Erickson P. What constitutes quality of life? Concepts and dimensions. Clin Nutr. 1988;7:53-63.

4. Patten SB, Kennedy SH, Lam RW, O'Donovan C, Filteau MJ, Parikh SV, Ravindran AV. Canadian Network for M, Anxiety T: Canadian Network for Mood and Anxiety Treatments (CANMAT) clinical guidelines for the management of major depressive disorder in adults. I. Classification, burden and principles of management. Journal of affective disorders. 2009: 117(Suppl 1):S5-14.

5. ten Doesschate MC, Koeter MW, Bockting CL, Schene AH, Group DS. Health related quality of life in recurrent depression: a comparison with a general population sample. J Affect Disord. 2010;120(1-3):126-32.

6. Katschnig H, Freeman HL, Sartorius N. Quality of life in mental disorders, 2nd ed. Edn. Chichester: Wiley; 2006.

7. De Fruyt J, Demyttenaere K. Quality of life measurement in antidepressant trials. Is there an added value? Psychother Psychosom. 2009:78(4):212-9.

8. Rapaport MH, Clary C, Fayyad R, Endicott J. Quality-of-life impairment in depressive and anxiety disorders. Am J Psychiatry. 2005;162(6):1171-8.

9. Wisniewski SR, Rush AJ, Bryan C, Shelton R, Trivedi MH, Marcus S, Husain MM, Hollon SD, Fava M, Investigators SD. Comparison of quality of life measures in a depressed population. J Nerv Ment Dis. 2007;195(3):219-25.

10. Souetre E, Martin P, Lozet H, Monteban H. Quality of life in depressed patients: comparison of fluoxetine and major tricyclic antidepressants. Int Clin Psychopharmacol. 1996;11(1):45-52

11. Gelenberg AJ, Freeman MP, Markowitz JC, Rosenbaum JF, Thase ME, Trivedi MH, Van Rhoads RS, Reus VI, Raymond DePaulo Jr M J, Fawcett JA. Practice guideline for the treatment of patients with major depressive disorder third edition. Am J Psychiatry. 2010;167(10):1-152.

12. Lin $\mathrm{CH}$, Lane HY, Chen CC, Juo SH, Yen CF. Early prediction of fluoxetine response for Han Chinese inpatients with major depressive disorder. J Clin Psychopharmacol. 2011;31(2):187-93.

13. APA: American Psychiatric Association: Structured Clinical Interview for DSM-IV. Washington, DC: American Psychiatric Press; 1994.

14. Hamilton M. A rating scale for depression. J Neurol Neurosurg Psychiatry. 1960;23:56-62

15. Guy W: ECDEU Assessment manual for psychopharmacology. Washington DC: DHEW Publication 76338; 1976.

16. Souery D, Amsterdam J, de Montigny C, Lecrubier Y, Montgomery S, Lipp O, Racagni G, Zohar J, Mendlewicz J. Treatment resistant depression: methodological overview and operational criteria. Eur Neuropsychopharmacol. 1999;9(1-2):83-91.

17. Schatzberg AF, Nemeroff CB. Essentials of clinical psychopharmacology. Washington, DC: American Psychiatric Pub; 2001.

18. Lingjaerde O, Ahlfors UG, Bech P, Dencker SJ, Elgen K. The UKU side effect rating scale $A$ new comprehensive rating scale for psychotropic drugs and a cross-sectional study of side effects in neuroleptic-treated patients. Acta Psychiatr Scand Suppl. 1987;334:1-100.

19. Pjrek E, Konstantinidis A, Assem-Hilger E, Praschak-Rieder N, Willeit M, Kasper S. Winkler D. Therapeutic effects of escitalopram and reboxetine in seasonal affective disorder: a pooled analysis. J Psychiatr Res. 2009;43(8):792-7.
20. Harrison $\mathrm{CL}$, Ferrier $\mathrm{N}$, Young $\mathrm{AH}$. Tolerability of high-dose venlafaxine in depressed patients. J Psychopharmacol. 2004;18(2):200-4.

21. Daly EJ, Trivedi MH, Fava M, Shelton R, Wisniewski SR, Morris DW, Stegman D, Preskorn SH, Rush AJ. The relationship between adverse events during selective serotonin reuptake inhibitor treatment for major depressive disorder and nonremission in the suicide assessment methodology study. J Clin Psychopharmacol. 2011;31(1):31-8.

22. Ware JE Jr, Sherbourne CD. The MOS 36-item short-form health survey (SF-36). I. Conceptual framework and item selection. Med Care. 1992:30(6):473-83.

23. Ware J.E. KM, Keller S.D. : SF-36 physical and mental health summary scales: a User's manual. Boston,MA: The Health Institute; 1994.

24. Ware JE, Kosinski M. Interpreting SF-36 summary health measures: a response. Qual Life Res. 2001:10(5):405-13. discussion 415-420

25. Tseng HM, Lu JF, Tsai YJ. Assessment of health-relate quality of life: ॥. Norming and validation of SF-36 Taiwan version. Taiwan Journal of Public Helth. 2003;22(2):512-8.

26. Cohen J. Statistical power analysis for the behavioral sciences. 2nd ed. Hillsdale, NJ: Lawrence Erlbaum; 1988.

27. Morris SB, DeShon RP. Combining effect size estimates in meta-analysis with repeated measures and independent-groups designs. Psychol Methods. 2002;7(1):105-25.

28. Faries D, Herrera J, Rayamajhi J, DeBrota D, Demitrack M, Potter WZ. The responsiveness of the Hamilton depression rating scale. J Psychiatr Res. 2000;34(1):3-10.

29. Forthofer RN, Lee ES, Hernandez M. Biostatistics : a guide to design, analysis, and discovery, 2nd ed. Edn. Amsterdam. London: Elsevier Academic Press; 2007.

30. IsHak WW, Greenberg JM, Balayan K, Kapitanski N, Jeffrey J, Fathy H, Fakhry $\mathrm{H}$, Rapaport MH. Quality of life: the ultimate outcome measure of interventions in major depressive disorder. Harv Rev Psychiatry. 2011;19(5): 229-39.

31. Kroenke K, West SL, Swindle R, Gilsenan A, Eckert GJ, Dolor R, Stang P, Zhou $\mathrm{XH}$, Hays $\mathrm{R}$, Weinberger $\mathrm{M}$. Similar effectiveness of paroxetine, fluoxetine, and sertraline in primary care - a randomized trial. Jama-Journal of the American Medical Association. 2001;286(23):2947-55.

32. Mann R, Gilbody S, Richards D. Putting the 'Q' in depression QALYs: a comparison of utility measurement using EQ-5D and SF-6D health related quality of life measures. Soc Psychiatry Psychiatr Epidemiol. 2009;44(7): 569-78.

33. Enns MW, Larsen DK, Cox BJ. Discrepancies between self and observer ratings of depression. The relationship to demographic, clinical and personality variables. J Affect Disord. 2000;60(1):33-41.

34. Moller HJ. Rating depressed patients: observer- vs self-assessment. Eur Psychiatry. 2000;15(3):160-72.

35. Dunlop BW, Li T, Kornstein SG, Friedman ES, Rothschild AJ, Pedersen R, Ninan $P$. Keller M. Correlation between patient and clinician assessments of depression severity in the PREVENT study. Psychiatry Res. 2010;177(1-2):177-83.

36. Moller HJ, von Zerssen D. Self-rating procedures in the evaluation of antidepressants. Psychopathology. 1995;28(6):291-306.

37. Giesecke T, Gracely RH, Williams DA, Geisser ME, Petzke FW, Clauw DJ. The relationship between depression, clinical pain, and experimental pain in a chronic pain cohort. Arthritis Rheum. 2005;52(5):1577-84.

38. Hotopf M, Mayou R, Wadsworth M, Wessely S. Temporal relationships between physical symptoms and psychiatric disorder. Results from a national birth cohort. The British journal of psychiatry : the journal of mental science. 1998;173:255-61.

39. Von Korff M, Simon G. The relationship between pain and depression. Br J Psychiatry Suppl. 1996;30:101-8.

40. Gureje O. Psychiatric aspects of pain. Curr Opin Psychiatry. 2007;20(1):42-6.

41. Hung Cl, Wang SJ, Liu CY. Validation of the depression and somatic symptoms scale by comparison with the short form 36 scale among psychiatric outpatients with major depressive disorder. Depress Anxiety. 2009:26(6):583-91.

42. Kroenke K, West SL, Swindle R, Gilsenan A, Eckert GJ, Dolor R, Stang P, Zhou $\mathrm{XH}$, Hays R, Weinberger M. Similar effectiveness of paroxetine, fluoxetine, and sertraline in primary care: a randomized trial. JAMA. 2001;286(23):2947-55.

43. Bech P, Tanghoj P, Cialdella P, Andersen HF, Pedersen AG. Escitalopram dose-response revisited: an alternative psychometric approach to evaluate clinical effects of escitalopram compared to citalopram and placebo in patients with major depression. The international journal of neuropsychopharmacology / official scientific journal of the Collegium Internationale Neuropsychopharmacologicum. 2004;7(3):283-90. 
44. Cao Y, Li W, Shen J, Malison RT, Zhang Y, Luo X. Health-related quality of life and symptom severity in Chinese patients with major depressive disorder. Asia Pac Psychiatry. 2013;5(4):276-83.

45. Kohler S, Unger T, Hoffmann S, Mackert A, Ross B, Fydrich T. The relationship of health-related quality of life and treatment outcome during inpatient treatment of depression. Quality of life research : an international journal of quality of life aspects of treatment, care and rehabilitation. 2015; 24(3):641-9.

46. Howard Kl, Lueger RJ, Maling MS, Martinovich Z. A phase model of psychotherapy outcome: causal mediation of change. J Consult Clin Psychol. 1993;61(4):678-85.

47. McCall WV, Rosenquist PB, Kimball J, Haskett R, Isenberg K, Prudic J, Lasater $B$, Sackeim HA. Health-related quality of life in a clinical trial of ECT followed by continuation pharmacotherapy: effects immediately after ECT and at 24 weeks. The journal of ECT. 2011;27(2):97-102.

48. Papakostas Gl, Petersen T, Mahal Y, Mischoulon D, Nierenberg AA, Fava M. Quality of life assessments in major depressive disorder: a review of the literature. Gen Hosp Psychiatry. 2004;26(1):13-7.

49. Reed C, Monz BU, Perahia DGS, Gandhi P, Bauer M, Dantchev N, Demyttenaere K, Garcia-Cebrian A, Grassi L, Quail D, et al. Quality of life outcomes among patients with depression after 6 months of starting treatment: results from FINDER. J Affect Disord. 2009;113(3):296-302.

50. Diehr PH, Derleth AM, McKenna SP, Martin ML, Bushnell DM, Simon G, Patrick DL. Synchrony of change in depressive symptoms, health status, and quality of life in persons with clinical depression. Health Qual Life Outcomes. 2006;4:27

51. McHorney CA, Ware JE Jr, Raczek AE. The MOS 36-item short-form health survey (SF-36): II. Psychometric and clinical tests of validity in measuring physical and mental health constructs. Med Care. 1993;31(3):247-63.

52. Moses T, Leuchter AF, Cook I, Abrams M. Does the clinical course of depression determine improvement in symptoms and quality of life? J Nerv Ment Dis. 2006;194(4):241-8.

53. Kaufman J, Martin A, King RA, Charney D. Are child-, adolescent-, and adultonset depression one and the same disorder? Biol Psychiatry. 2001;49(12): 980-1001.

54. Zisook S, Lesser I, Stewart JW, Wisniewski SR, Balasubramani GK, Fava M, Gilmer WS, Dresselhaus TR, Thase ME, Nierenberg AA, et al. Effect of age at onset on the course of major depressive disorder. Am J Psychiatry. 2007; 164(10):1539-46

55. Klein DN, Schatzberg AF, McCullough JP, Dowling F, Goodman D, Howland $\mathrm{RH}$, Markowitz JC, Smith C, Thase ME, Rush AJ, et al. Age of onset in chronic major depression: relation to demographic and clinical variables, family history, and treatment response. J Affect Disord. 1999;55(2-3):149-57.

56. Miller IW, Keitner Gl, Schatzberg AF, Klein DN, Thase ME, Rush AJ, Markowitz JC, Schlager DS, Kornstein SG, Davis SM, et al. The treatment of chronic depression, part 3: psychosocial functioning before and after treatment with sertraline or imipramine. The Journal of clinical psychiatry. 1998;59(11):608-19.

57. Fava M, Mallinckrodt $\mathrm{CH}$, Detke MJ, Watkin JG, Wohlreich MM. The effect of duloxetine on painful physical symptoms in depressed patients: do improvements in these symptoms result in higher remission rates? The Journal of clinical psychiatry. 2004;65(4):521-30.

58. Berlim MT, McGirr A, Fleck MP. Can sociodemographic and clinical variables predict the quality of life of outpatients with major depression? Psychiatry Res. 2008;160(3):364-71.

59. Barge-Schaapveld DQ, Nicolson NA. Effects of antidepressant treatment on the quality of daily life: an experience sampling study. The Journal of clinical psychiatry. 2002;63(6):477-85.

60. Cheung AH, Levitt AJ, Szalai JP. Impact of antidepressant side effects on adolescent quality of life. Can J Psychiatry. 2003:48(11):727-33.

61. Beasley CM Jr, Nilsson ME, Koke SC, Gonzales JS. Efficacy, adverse events, and treatment discontinuations in fluoxetine clinical studies of major depression: a meta-analysis of the 20-mg/day dose. The Journal of clinical psychiatry. 2000;61(10):722-8.

62. Uzun S, Kozumplik O. Management of side effects of antidepressants - brief review of recommendations from guidelines for treatment of major depressive disorder. Psychiatr Danub. 2009;21(1):91-4.
63. Walsh BT, Seidman SN, Sysko R, Gould M. Placebo response in studies of major depression: variable, substantial, and growing. JAMA. 2002;287(14): 1840-7.

64. Khan A, Leventhal RM, Khan SR, Brown WA. Severity of depression and response to antidepressants and placebo: an analysis of the Food and Drug Administration database. J Clin Psychopharmacol. 2002;22(1):40-5.

65. Kirsch I, Deacon BJ, Huedo-Medina TB, Scoboria A, Moore TJ, Johnson BT. Initial severity and antidepressant benefits: a meta-analysis of data submitted to the Food and Drug Administration. PLoS Med. 2008:5(2):e45.

\section{Submit your next manuscript to BioMed Central and we will help you at every step:}

- We accept pre-submission inquiries

- Our selector tool helps you to find the most relevant journal

- We provide round the clock customer support

- Convenient online submission

- Thorough peer review

- Inclusion in PubMed and all major indexing services

- Maximum visibility for your research

Submit your manuscript at www.biomedcentral.com/submit
Biomed Central 